\title{
GC-MS Method for Quantification and Pharmacokinetic Study of Four Volatile Compounds in Rat Plasma after Oral Administration of Commiphora myrrh (Nees) Engl. Resin and In Vitro Cytotoxic Evaluation
}

\author{
Ali S. Alqahtani ${ }^{1, *(\mathbb{D})}$, Rashed N. Herqash ${ }^{1, *(\mathbb{D}}$, Faleh Alqahtani ${ }^{2} \mathbb{D}$, Syed Rizwan Ahamad ${ }^{3}$, Fahd A. Nasr ${ }^{1}$ (D) \\ and Omar M. Noman ${ }^{1}$ D \\ 1 Department of Pharmacognosy, College of Pharmacy, King Saud University, Riyadh 11451, Saudi Arabia; \\ fnasr@ksu.edu.sa (F.A.N.); onoman@ksu.edu.sa (O.M.N.) \\ 2 Department of Pharmacology and Toxicology, College of Pharmacy, King Saud University, \\ Riyadh 11451, Saudi Arabia; afaleh@ksu.edu.sa \\ 3 Department of Pharmaceutical Chemistry, College of Pharmacy, King Saud University, \\ Riyadh 11451, Saudi Arabia; srahamad@ksu.edu.sa \\ * Correspondence: alalqahtani@ksu.edu.sa (A.S.A.); rherqash@ksu.edu.sa (R.N.H.); \\ Tel.: +966-14670742 (R.N.H.)
}

check for updates

Citation: Alqahtani, A.S.; Herqash, R.N.; Alqahtani, F.; Ahamad, S.R.; Nasr, F.A.; Noman, O.M. GC-MS Method for Quantification and Pharmacokinetic Study of Four Volatile Compounds in Rat Plasma after Oral Administration of Commiphora myrrh (Nees) Engl. Resin and In Vitro Cytotoxic Evaluation. Separations 2021, 8, 239. https://doi.org/10.3390/ separations 8120239

Academic Editor: Igor Clarot

Received: 9 November 2021

Accepted: 2 December 2021

Published: 7 December 2021

Publisher's Note: MDPI stays neutral with regard to jurisdictional claims in published maps and institutional affiliations.

Copyright: (c) 2021 by the authors. Licensee MDPI, Basel, Switzerland. This article is an open access article distributed under the terms and conditions of the Creative Commons Attribution (CC BY) license (https:// creativecommons.org/licenses/by/ $4.0 /)$.

\begin{abstract}
A rapid, simple, and sensitive gas chromatography-tandem mass spectrometry (GC-MS) method was established and validated for simultaneous determination of four volatile compounds, namely curzerene, methoxyfuranodiene, $\beta$-elemene, and $\alpha$-pinene in rat plasma samples after oral administration of the resin extract of Commiphora myrrh using limonene as an internal standard (IS). Liquid-liquid extraction using hexane and ethyl acetate (1:1) mixture as an extracting agent was used for the samples extraction procedure. The GC-MS system was operated under selective ion monitoring (SIM) mode using Perkin Elmer Elite 5MS column $(30 \mathrm{~m} \times 0.25 \mathrm{~mm} \times 0.25 \mu \mathrm{m}$ film thickness). Specificity, linearity, precision, accuracy, extraction recovery, and stability were used to validate the developed method. The assay showed good linearity $\left(r^{2} \geq 0.998\right)$, and the lowest limits of quantification (LLOQ) were $3.97-21.38 \mathrm{ng} / \mathrm{mL}$ for the four analytes. This assay was successfully applied to pharmacokinetic studies of the four volatile compounds in rat plasma. The antiproliferative activity of these volatile compounds was evaluated against lung carcinoma (A549) and colon (LoVo) cell lines, were each compound caused variable inhibition on cells proliferation and methoxyfuranodiene exerted the strong antiproliferative activity against both cell line according to $\mathrm{IC}_{50}$ values.
\end{abstract}

Keywords: Commiphora myrrh; GC-MS; plasma; pharmacokinetics; antiproliferative activity

\section{Introduction}

Commiphora myrrha (Nees) Engl. is a medicinal plant belonging to the genus Commiphora (Burseraceae family) and mainly grows in Yemen and the southern regions of Saudi Arabia [1,2]. C. myrrh is known to produce a natural compound (oleo-gum-resin), known as myrrh $[3,4]$. Myrrh, as traditional natural medicine, has been used to treat various diseases, such as amenorrhea, ache, dysmenorrhea, tumors, fever, stomach complaints, gall bladder, chest ailments, snake and scorpion bites, and skin infections in ancient India, China, Rome, Greece, and Babylon [5]. Previous investigations have revealed the myrrh can be used in the treatment of ulcers, Schistosoma, Fasciolopsis, respiratory catarrh, furunculosis, and diabetes [6-8]. Myrrh was also found to promote the permeability of the medicine from epidermis to dermal capillaries and also enhance the wound healing process [9].

The Myrrh's Gum-resin-volatile oil are the major useful contents, where it contains (30-60\%) gum including acidic polysaccharides, resin (25-40\%), volatile oil (3-8\%), 
eugenol, heerabolene and many furansesquiterpenes [4,10]. In the previous studies, the volatile constituents of myrrh were identified [11-13]. Among these volatile constituents, curzerene, methoxyfuranodiene, $\beta$-elemene and $\alpha$-pinene are the key bioactive compounds [1,11,14-17], and primarily responsible for a wide range of reported pharmacological activities of myrrh. Curzerene has been verified that it has primarily responsible for the analgesic activity of myrrh [3]. methoxyfuranodiene was found that it has antioxidant and anti-angiogenic effects $[4,18]$. $\beta$-Elemene was widely used for removing blood stasis and it has an anti-tumor effect [19-21]. $\alpha$-Pinene has a wide range of reported pharmacological activities, including antibacterial, anticoagulant, antitumor, antimicrobial, antimalarial, antioxidant, anti-inflammatory, anti-Leishmania, and analgesic effects [22].

Herbal medications have been utilized for preventing and treating diseases for hundreds of years. Recently, these drugs are becoming more popular globally. As being nature-derived is the essential attribute of herbal medicines, people believe that taking them for diseases treatment is safe enough and has no side effects. However, the efficacy of herbal resourced compounds depends on the constituents in the body and their pharmacokinetics [23], that is why we were encouraged to analyze the more predominant volatile constituent of $C$. myrrh resin extract in form of pharmacokinetic studies which could provide valuable references for determining the appropriate utilization of $C$. myrrh resin.

To our knowledge, there is no method about the determination of curzerene and methoxyfuranodiene (isolated in our lab) in plasma in the form of pharmacokinetic studies is available in the literatures. In comparison, the previous studies have discussed the pharmacokinetics of $\beta$-elemene and $\alpha$-pinene in plasma (human or rat) samples using GC-MS method after administration of different herbal materials (e.g., Rhizoma curcumae and Mastered Oil) [24-26], while our study was conducted to determine $\beta$-elemene and $\alpha$-pinene after oral administration of $C$. myrrh resin extract. It is worth mentioning here that multiple constituents in various medicinal plant extracts (including C. myrrh resin) could influence the bioavailability, metabolism, and half-life of $\beta$-elemene and $\alpha$-pinene [23,27], therefore a better understanding of the pharmacokinetics parameters and bioavailability of those compounds would also provide a significant experimental basis for the proper clinical application of myrrh and predict the influence of pharmacokinetic interactions with the multiple constituents $C$. myrrh resin.

A simple, sensitive, and selective gas chromatography-mass spectrometry method (GC-MS) in selected ion mode (SIM) was established for the simultaneous quantification of curzerene, methoxyfuranodiene, $\beta$-elemene, and $\alpha$-pinene in rat plasma. The antiproliferative activity of these volatile compounds was evaluated against lung and colon cancer cell lines. The demonstrated method can be applied successfully for pharmacokinetics studies of those bioactive compounds after oral administration of $C$. myrrh resin extract. We expect that the results of this study would provide some references for further pharmacological application of $C$. myrrh resin to enhance efficacy, decrease toxicity, and support therapeutic drug monitoring (TDM).

\section{Materials and Methods}

\subsection{Plant Material}

The C. myrrh resin (myrrh) is the thickened, bitter-tasting, yellowish-brown agreeably aromatic gum exudes as a fluid from resin ducts in the tree bark when the bark splits naturally or is cut in tapping. Upon exposure to the air, hardens and turns reddishbrown irregular chunks called tears, which are then collected from the tree. Myrrh sample was purchased from Alothim Market in Riyadh, Saudi Arabia. It was identified and verified by Prof. Ramzi mothana. A vouchered sample (no. 12486) was deposited in the herbarium of Medicinal, Aromatic, and Poisonous Plants Research Center, Department of Pharmacognosy King Saud University, Riyadh, Saudi Arabia. 


\subsection{Chemicals and Reagents}

Standard of curzerene (purity $\geq 99 \%$ ) was purchased from Biopurify phytochemicals Co., Ltd. (Chengdu, Sichuan, China). Standard of $\beta$-elemene (purity $\geq 99 \%$ ) was purchased from Cayman Chemical Co., Ltd. (Ann Arbor, MI, USA). $\alpha$-pinene (purity $\geq 98 \%$ ) was obtained from Fluka Chemie GmbH (Buchs, Switzerland). A white crystalline methoxyfuranodiene was isolated and identified in previous work [4]. Methanol and acetonitrile (HPLC grade) were obtained from Sigma Co., Ltd. (St. Louis, MO, USA). Ultra-pure water was purified by Purelab Flex water purification system (Veolia Ltd., High Wycombe, UK).

\subsection{Preparation of Calibration Standards and Quality Control Samples}

Standard stock solutions of curzerene $(200 \mu \mathrm{g} / \mathrm{mL})$, methoxyfuranodiene $(1.5 \mathrm{mg} / \mathrm{mL})$, $\beta$-elemene $(250 \mu \mathrm{g} / \mathrm{mL})$, and $\alpha$-pinene $(2 \mathrm{mg} / \mathrm{mL})$ were prepared in methanol. Then, gradient concentrations of the standard stock solutions were prepared by serial dilution with $90 \%$ methanol/water. The internal standard (IS) solution of limonene was prepared to the concentration of $250 \mathrm{ng} / \mathrm{mL}$ in methanol. The calibration solutions were prepared by serial dilution with blank rat plasma to obtain the concentrations ranging from 325.0 to $10.16 \mathrm{ng} / \mathrm{mL}$ for curzerene, $252.0-7.88 \mathrm{ng} / \mathrm{mL}$ for methoxyfuranodiene, $684.0-21.38 \mathrm{ng} / \mathrm{mL}$ for $\beta$-elemene, and $127.0-3.97 \mathrm{ng} / \mathrm{mL}$ for $\alpha$-pinene. The Quality control (QC) samples concentration were $10.20,81.30,162 \mathrm{ng} / \mathrm{mL}$ for curzerene, $7.90,63,126 \mathrm{ng} / \mathrm{mL}$ for methoxyfuranodiene, $21.40,171,342 \mathrm{ng} / \mathrm{mL}$ for $\beta$-elemene and $8,31.80,127 \mathrm{ng} / \mathrm{mL}$ for $\alpha$-pinene. All standard working solutions were stockpiled at $4{ }^{\circ} \mathrm{C}$, then they were returned to room temperature before analysis.

\subsection{GC-MS Apparatus and Analysis Conditions}

GC-MS analysis was performed using a Perkin Elmer GC Calarus 600T combined with a Clarus 600T single quadrupole mass spectrometer. Separation was performed on a Perkin Elmer Elite 5MS column $(30 \mathrm{~m} \times 0.25 \mathrm{~mm} \times 0.25 \mu \mathrm{m}$ film thickness), with high-purity helium as the gas carrier, at a flow rate of $1 \mathrm{~mL} / \mathrm{min}$. The injector temperature was $280^{\circ} \mathrm{C}$ and it was equipped with a splitless injector at 20:1. The temperature was set initially to $40{ }^{\circ} \mathrm{C}$ (held for $1 \mathrm{~min}$ ), then was increased to $150{ }^{\circ} \mathrm{C}$ at $20^{\circ} \mathrm{C} \mathrm{min}^{-1}$ (held for $1 \mathrm{~min}$ ), then increased further to $300{ }^{\circ} \mathrm{C}$ at $20^{\circ} \mathrm{C} \mathrm{min}-1$ for $1 \mathrm{~min}$. The MS ion source temperature was $220^{\circ} \mathrm{C}$ and the inlet line temperature was set to $240^{\circ} \mathrm{C}$. The mass detector was operated at $70 \mathrm{eV}$ ionization energy and the solvent delay of $3 \mathrm{~min}$. The selective ion monitoring (SIM) was set for quantification and the total time required for analyzing a single sample was $16 \mathrm{~min}$.

\subsection{Assay of the Four Volatile Compounds in Myrrh Extract}

The contents of curzerene, methoxyfuranodiene, $\beta$-elemene, and $\alpha$-pinene in the C. myrrh resin extract were quantitatively measured by GC-MS. The crude C. myrrh resin was extracted according to our previously described method [2,4]. Briefly, the dried oleogum resin of $C$. myrrh $(1 \mathrm{~kg})$ was extracted with $2 \mathrm{~L}$ of ethanol (95\%) for 3 days using cold maceration. The obtained alcoholic extract was filtered, dried using a rotatory evaporator, and then diluted. Finally, $1 \mu \mathrm{L}$ of the filtrate was injected into the GC-MS system.

\subsection{Animal Experiments and Drug Administration}

Animal experiments were performed in line with the "guidelines of the animal care and use committee at King Saud University" and the protocol was authorized by approval from Research Ethics Committee (Reference no. KSU-SE-21-15, dated 3 February 2021). Male SPF Wistar albino rats weighing between 200-250 g were obtained from the "Animal care center, College of Pharmacy, King Saud University, Riyadh, Saudi Arabia". Rats were housed on a standard chow diet in a room free from any source of chemical contamination, artificially illuminated ( $12 \mathrm{~h}$ dark/light cycle) under ambient temperature- and humidity environment $\left(23 \pm 2{ }^{\circ} \mathrm{C}, 50 \%\right.$ relative humidity) at the animal facility. The single oral administration was prepared by constituting the extract with carboxyl methyl cellulose 
$(0.5 \%, w / v)$ to acquire an oral formulation in form of suspension with a concentration equivalent to $500 \mathrm{mg} / \mathrm{kg} \mathrm{C.} \mathrm{myrrh} \mathrm{resin.} \mathrm{Rats} \mathrm{were} \mathrm{administered} \mathrm{orally} \mathrm{the} \mathrm{suspended}$ extract using gastric gavage needle no. 24.

\subsection{Extraction Procedure for Plasma Samples}

After frozen plasma samples were thawed and allowed to equilibrate at room temperature, an aliquot of $200 \mu \mathrm{L}$ plasma sample was mixed with $10 \mu \mathrm{L}$ of IS solution (limonene, $250 \mathrm{ng} / \mathrm{mL}$ ) in a 1.5-mL Eppendorf tube. The sample was shaken for $30 \mathrm{~s}$ and $300 \mu \mathrm{L}$ of hexane and ethyl acetate (1:1) mixture was added and vortex-mixed for $60 \mathrm{~s}$, then transferred for cold centrifugation $\left(4^{\circ} \mathrm{C}\right)$ at 10,000 rpm for $10 \mathrm{~min}$. After, centrifugation the acquired supernatant was dried into a sample concentrator at $43{ }^{\circ} \mathrm{C}$ temperature. The residue was reconstituted in $100 \mu \mathrm{L}$ acetonitrile and water $(90: 20, v / v)$ mixture and vortex-mixed for $2 \mathrm{~min}$. Finally, the dissolved sample was centrifuged at 12,000 rpm for $10 \mathrm{~min}$, and an aliquot $(1 \mu \mathrm{L})$ of the supernatant was injected into the GC-MS/MS system for analysis.

\subsection{Method Validation}

The developed GC-MS assay was validated for selectivity, linearity, within-day and between-day precision, accuracy, recovery, and stability in accordance with US FDA bioanalytical method validation guidance [28].

\subsubsection{Selectivity and Specificity}

Blank plasma samples spiked with the IS were analyzed to investigate the interferences from endogenous substances or IS. Specificity and selectivity of the method were tested by comparing the chromatograms of six batches of blank plasma from six individual rats, corresponding plasma samples added with the 4 analytes and IS, and plasma samples from the rats $2 \mathrm{~h}$ after oral administration of $C$. myrrh resin extract.

\subsubsection{Linearity and LLOQ}

Standard plasma samples at series concentrations were analyzed to assess the linearity. The calibration curve was constructed by plotting the peak area ratio (y) of each analyte to IS versus the corresponding plasma concentrations ( $\mathrm{x}$ ) using a weighted least-squares linear regression model $\left(1 / \mathrm{x}^{2}\right)$. At the lower concentration on the standard analytical curve (LLOQ), the acceptable precision (relative standard deviation, RSD) and accuracy (relative error, RE) should be within $\pm 20 \%$.

\subsubsection{Precision and Accuracy}

The intra- and inter-day precisions were evaluated by RSD, and determined by analyzing three concentrations levels (low, medium, and high) of QC samples. Five replicates were measured on the same day and the three consecutive days, respectively. The precisions were expressed as the RSD, and the accuracy was determined by RE. The acceptable criteria for the precisions and accuracy were required to be within $15 \%$ for three concentrations levels.

\subsubsection{Extraction Recovery and Matrix Effect}

In order to investigate the extraction recoveries, the peak areas obtained from five plasma samples spiked with analytes and IS were compared before and after extraction at three QC levels. The matrix effect was assessed by comparing the peak areas obtained from the plasma matrix (analytes and IS were added) with the corresponding pure working solutions at identical concentrations.

\subsection{Application of the Validated Assay in Pharmacokinetic Study}

The developed method in plasma samples was successfully applied in pharmacokinetic studies of the four investigated analytes in rats. Animals were fasted overnight prior to the experiment to assure a more uniform drug absorption by preventing mixing test compounds with food. Blood samples (about $0.3 \mathrm{~mL}$ ) were gathered into heparinized 
Eppendorf tube from the lateral saphenous vein at 0, 0.25, 0.5, 1.0, 2.0, 3.0, 5.0, 8.0, 12.0, and $24.0 \mathrm{~h}$ intervals after oral administration. Plasma was separated immediately by centrifugation at $10,000 \mathrm{rpm}$ for $10 \mathrm{~min}$ and stored at $-80^{\circ} \mathrm{C}$ until analysis.

The pharmacokinetic parameters were measured by performing a non-compartment model using PKSolver software. The peak drug plasma concentration $\left(\mathrm{C}_{\max }\right)$, time to achieve $\mathrm{C}_{\max }\left(\mathrm{T}_{\max }\right)$, area under plasma concentration-time curve zero to time and infinity $\left(\mathrm{AUC}_{0-\mathrm{t}} ; \mathrm{AUC}_{0-\infty}\right)$, elimination half-life $\left(\mathrm{T}_{\frac{1}{2}}\right)$, elimination rate constant $(\mathrm{Kel})$, and mean residence time were calculated. Statistical parameters including mean, standard deviation (SD), and \% RSD were calculated using Excel 2013 (Microsoft Office Professional Plus 2013).

\subsection{Cytotoxicity Assay}

Cytotoxic activity was assessed using MTT assay as described by Nasr et al. [29]. In brief, A549 (lung) and LoVo (colon) cancer cells were seeded into 96-well plates at a density of $5 \times 104$ cells in $100 \mu \mathrm{L}$ medium per well and were allowed $24 \mathrm{~h}$ to attach to the bottom. After treatment with each compound, the plates were incubated at $37^{\circ} \mathrm{C}\left(5 \% \mathrm{CO}_{2}, 95 \%\right.$ humidity) for $48 \mathrm{~h}$. Then, MTT solution ( $10 \mu \mathrm{L}, 5 \mathrm{mg} / \mathrm{mL}$ in PBS) was added and the plates were incubated again for $2 \mathrm{~h}$. Thereafter, isopropanol was added containing $0.01 \mathrm{M} \mathrm{HCL}$ to dissolve the formazan production in the cells. The plates were then allowed to sit for $10 \mathrm{~min}$ at plate shaker and absorbance measuring was taken at $570 \mathrm{~nm}$ using BioTek plate reader. The $\mathrm{IC}_{50}$ values were determined by OriginPro 8.5 software from a dose-response curve.

\section{Results and Discussion}

\subsection{Optimization of GC-MS Conditions}

To optimize the processing conditions of the mass spectrometer, the standard solution of each analyte and the IS were separately infused into the mass spectrometer. The selective ions for different analytes were 108/148 for curzerene, 123/246 for methoxyfuranodiene, $81 / 147$ for $\beta$-elemene, $93 / 136$ for $\alpha$-pinene, and $67 / 121$ for the IS. The MS spectra in scan mode were performed from 50-600 mass range and MS spectra of the four analytes and IS are presented in Figure 1. In order to obtain the best sensitivity, symmetrical peaks, and reduced run time, instrumental parameters such as injector temperature, detector temperature, initial column temperature, as well as the final column temperature, and split ratio were also optimized.

\subsection{Contents of the Four Analytes in Myrrh Extract}

The analytical data showed that the contents of curzerene, methoxyfuranodiene, $\beta$-elemene, and $\alpha$-pinene (Figure 2 ) in C. myrrh resin extract were $0.153,0.093,0.046$, and $0.023 \mathrm{mg} / \mathrm{g}$, respectively. Quantitative results also indicated that curzerene, was the more predominant constituent in C. myrrh resin extract (Figure 3).

\subsection{Optimization of Sample Extraction Method}

Due to their different concentrations, dissolution properties, and $\mathrm{pKa}$ values as well as stabilities in the biological matrix, the extraction procedure for the analytes in plasma was optimized, and the extraction procedure should be simple, reproducible, minimize matrix effects, timesaving, and obtain a good recovery for all analytes. To obtain the desired recovery of all analytes, liquid-liquid extraction (LLE) was tried because this method could concentrate the analytes. For LLE, solvents including ethyl acetate, n-hexane, diethyl ether, and dichloromethane were investigated as extracting agents. We found that sample pretreatment using a mixture of hexane and ethyl acetate (1:1) could achieve good reproducibility and recovery for the four analytes.

\subsection{Method Validation}

\subsubsection{Selectivity}

The typical chromatograms acquired from blank plasma, blank plasma spiked with the 4 analytes and IS, and plasma sample from a rat at $2 \mathrm{~h}$ following oral administration 
of the C. myrrh resin extract are presented in Figure 4. From the typical chromatograms with good separation and excellent peak shapes, we saw that there are no interfering peaks from endogenous compounds at the retention times of the four analytes and IS. These results indicated that the developed method is selective and specific for these four analytes. The retention times of the four analytes and IS were as followed: $\alpha$-pinene, $\beta$-elemene, curzerene, methoxyfuranodiene, and IS were 8.86, 12.86, 13.71, 15.20, and $9.70 \mathrm{~min}$, respectively.

\subsubsection{Assay Linearity and Sensitivity}

The equation of the calibration curves, coefficient of determination $\left(\mathrm{r}^{2}\right)$, linearity ranges, and LLOQs for the four analytes are listed in Table 1. Good linearity within the described ranges for the four analytes was indicated from the high coefficient of determination $\left(\mathrm{r}^{2}\right)$ value $(\geq 0.998)$. For pharmacokinetic studies, the LLOQs were sufficient enough for the quantitative determination of the four analytes in plasma.

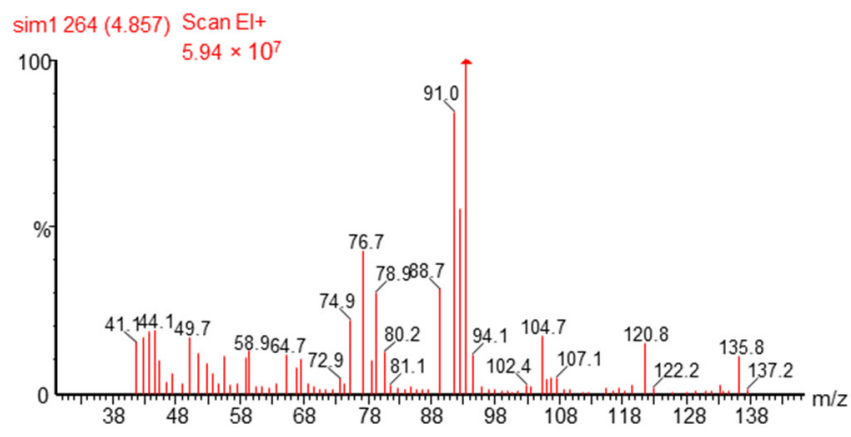

A
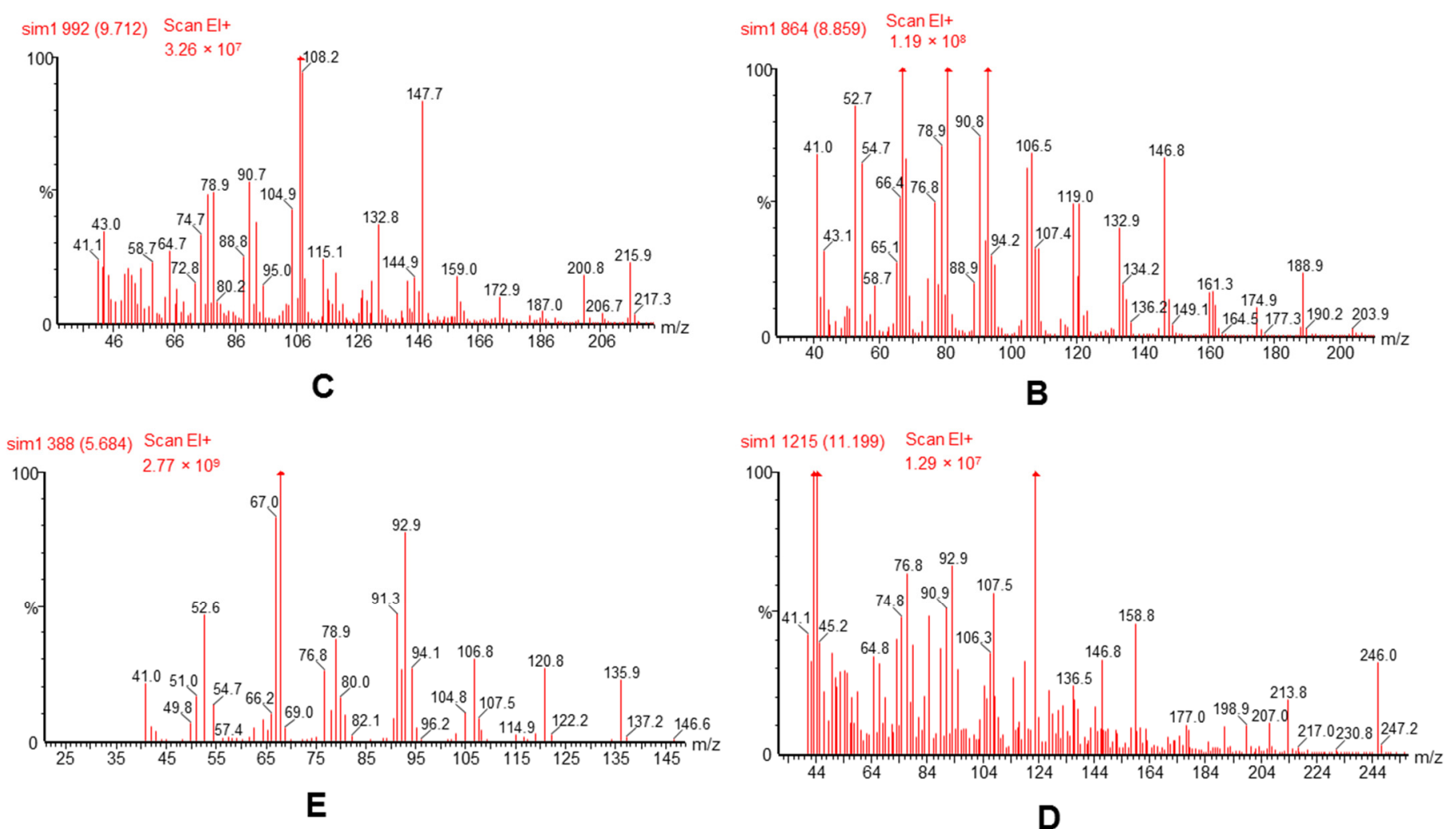

Figure 1. Product ion mass spectrums of the four analytes and internal standard: $\alpha$-pinene (A), $\beta$-elemene (B), curzerene (C), methoxyfuranodiene (D), and I.S (E). 

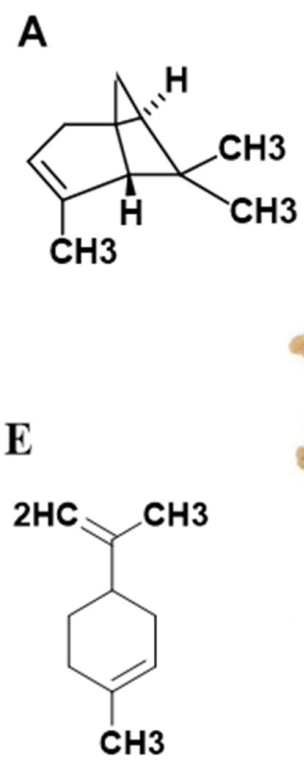

\section{.}
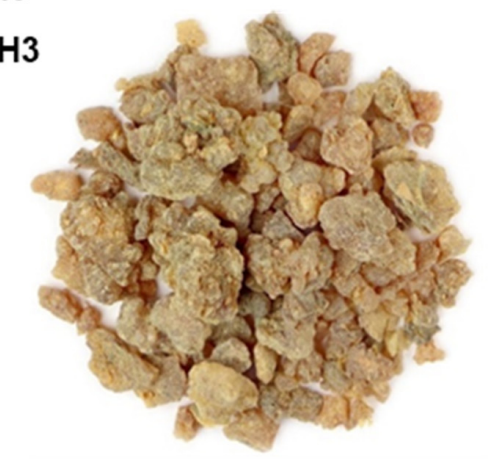

D

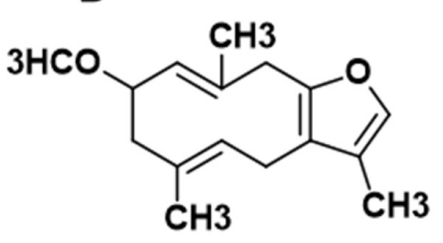

B

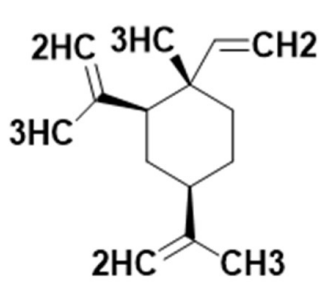

C<smiles>[CH]C=CC1(C)Cc2occ(C)c2CC1C(=C)C</smiles>

Figure 2. The picture of C. myrrh resin and chemical structures of $\alpha$-pinene (A), $\beta$-elemene (B), curzerene (C), methoxyfuranodiene (D), and I.S. (E).

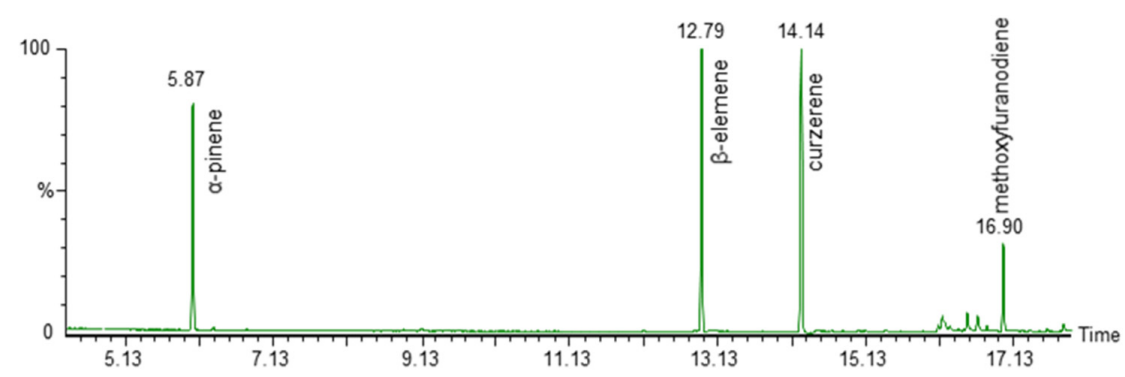

A

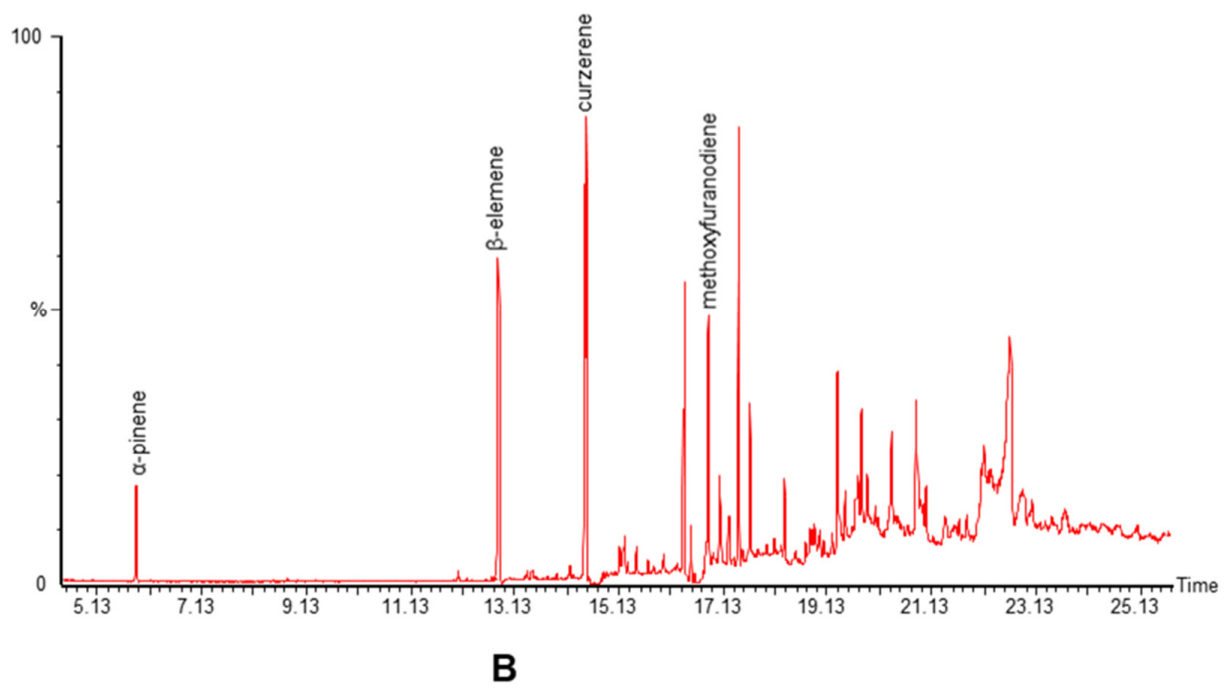

Figure 3. GC/MS chromatograms of standard analyzed compounds (A), and C. myrrh resin extract (B). 


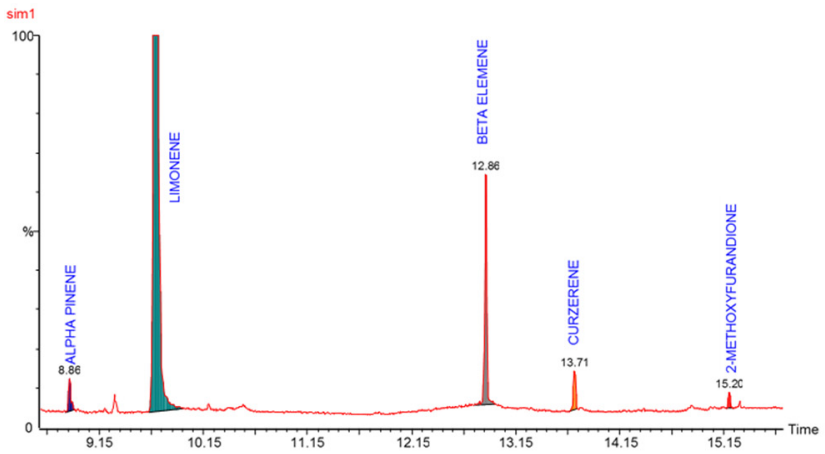

(A)

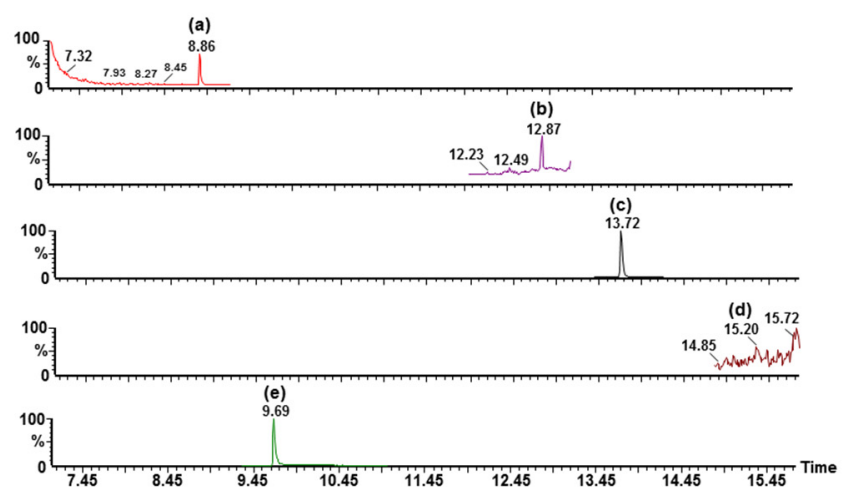

(D)

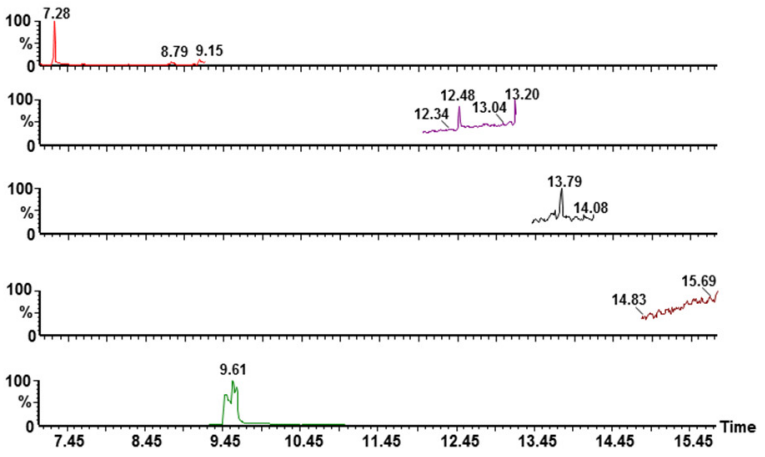

(B)

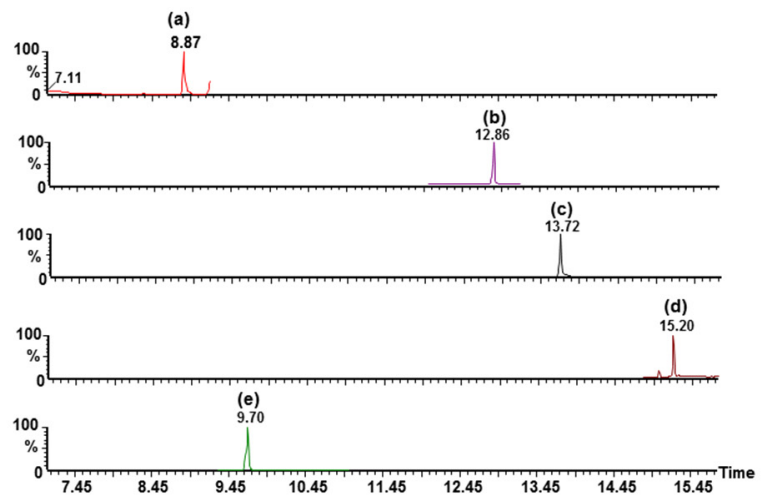

(C)

Figure 4. Selected ion monitoring chromatograms of the four analytes and IS (A), blank rat plasma (B), blank rat plasma spiked with the four analytes at the LLOQ and IS (C), and rat plasma samples at $2 \mathrm{~h}$ after oral administration of $C$. myrrh resin extract (D). Peaks: (a) $\alpha$-pinene, (b) $\beta$-elemene, (c) curzerene, (d) methoxyfuranodiene, and (e) limonene (IS).

Table 1. The regression data, linear ranges and LLOQs of the four analytes in rat plasma.

\begin{tabular}{ccccc}
\hline Analyte. & Regression Equation & Range $(\mathbf{n g} / \mathbf{m L})$ & Correlation Coefficient $\left(\mathbf{r}^{2}\right)$ & LLOQs $(\mathbf{n g} / \mathbf{m L})$ \\
\hline Curzerene & $\mathrm{y}=0.0747 x-0.0064$ & $10.16-325.0$ & 0.9989 & 10.16 \\
\hline Methoxyfuranodiene & $\mathrm{y}=0.0363 \mathrm{x}-0.0127$ & $7.88-252.0$ & 0.9981 & 7.88 \\
\hline$\beta$-Elemene & $\mathrm{y}=0.2011 \mathrm{x}-0.1613$ & $21.38-684.0$ & 0.9987 & 21.38 \\
\hline$\alpha$-Pinene & $\mathrm{y}=0.0502 \mathrm{x}-0.011$ & $3.97-127.0$ & 0.9984 & 3.97 \\
\hline
\end{tabular}

\subsubsection{Precision and Accuracy}

Table 2 illustrates a summarize of precision and accuracy data for all four analytes at their three different QC levels (low, medium, and high). The within-day (intraday) and between-day (interday) precisions (RSD) for curzerene, methoxyfuranodiene, $\beta$-elemene, and $\alpha$-pinene were found to be $\leq 7.23, \leq 6.85, \leq 4.92$, and $\leq 14.58 \%$, respectively. Within-day and between-day accuracy (RE) were ranged from -4.49 to $8.68 \%$ and from $-5.08-5.15 \%$, respectively. These results indicated that the developed method was accurate and precise for the determination of the tested analytes and therefore appropriate for routine pharmacokinetic analysis. 
Table 2. Intra- and inter-day precisions and accuracies of the four analytes from QC samples prepared in rat plasma $(\mathrm{n}=5)$.

\begin{tabular}{|c|c|c|c|c|c|c|c|}
\hline \multirow[b]{2}{*}{ Analyte } & \multirow{2}{*}{$\begin{array}{l}\text { Nominal Conc } \\
(\mathrm{ng} / \mathrm{mL})\end{array}$} & \multicolumn{3}{|c|}{ Intra-Day } & \multicolumn{3}{|c|}{ Intre-Day } \\
\hline & & Observed & $\begin{array}{l}\text { Precision } \\
\text { (RSD, \%) }\end{array}$ & $\begin{array}{c}\text { Accuracy } \\
(\mathrm{RE}, \%)\end{array}$ & Observed & $\begin{array}{l}\text { Precision } \\
\text { (RSD, \%) }\end{array}$ & $\begin{array}{c}\text { Accuracy } \\
(\mathrm{RE}, \%)\end{array}$ \\
\hline \multirow{3}{*}{ Curzerene } & 10.20 & $10.78 \pm 0.36$ & 3.37 & 5.68 & $9.80 \pm 0.56$ & 5.74 & -3.92 \\
\hline & 81.30 & $83.06 \pm 3.18$ & 3.83 & 2.16 & $83.51 \pm 6.04$ & 7.23 & 2.71 \\
\hline & 162.00 & $156.89 \pm 5.65$ & 3.60 & -3.16 & $166.63 \pm 6.96$ & 4.18 & 2.86 \\
\hline \multirow{3}{*}{ Methoxyfuranodiene } & 7.90 & $8.32 \pm 0.71$ & 0.82 & 5.31 & $7.50 \pm 0.41$ & 5.50 & -5.08 \\
\hline & 63.00 & $64.41 \pm 2.97$ & 4.61 & 2.24 & $64.39 \pm 1.40$ & 2.18 & 2.20 \\
\hline & 126.00 & $120.85 \pm 4.83$ & 3.99 & -4.08 & $132.49 \pm 9.08$ & 6.85 & 5.15 \\
\hline \multirow{3}{*}{$\beta$-Elemene } & 21.40 & $21.71 \pm 0.87$ & 4.00 & 1.44 & $20.47 \pm 0.51$ & 2.50 & -4.34 \\
\hline & 171.00 & $174.59 \pm 7.58$ & 4.34 & 2.10 & $175.24 \pm 2.80$ & 1.60 & 2.48 \\
\hline & 342.00 & $326.63 \pm 9.89$ & 3.03 & -4.49 & $339.44 \pm 16.44$ & 4.92 & -0.75 \\
\hline \multirow{2}{*}{$\alpha$-Pinene } & 8.00 & $8.69 \pm 1.27$ & 14.58 & 8.68 & $7.70 \pm 0.90$ & 11.70 & -3.77 \\
\hline & 31.80 & $31.44 \pm 1.37$ & 4.36 & -1.15 & $31.18 \pm 0.77$ & 2.48 & -1.95 \\
\hline
\end{tabular}

\subsubsection{Recovery and Matrix Effects}

The recovery and matrix effects of four analytes at level QC samples were listed in Table 3. The mean recoveries of the four analytes in the rat plasma sample were between $77.08 \%$ and $92.94 \%$, and the mean matrix effects ranged from $83.10 \%$ to $101.15 \%$. As for IS, the extraction recovery and matrix effects were $82.9 \%$ and $91.5 \%$, respectively. Furthermore, all of the RSD values were less than $9.14 \%$. Obviously, the sample pretreatment was suitable to obtain stable and high extraction recovery and no significant co-eluting endogenous interference existed in the plasma.

Table 3. Extraction efficiency (recovery), and matrix effect of four analytes in rat plasma $(n=5)$.

\begin{tabular}{|c|c|c|c|c|c|}
\hline \multirow{2}{*}{ Analyte } & \multirow{2}{*}{$\begin{array}{l}\text { Nominal Conc } \\
(\mathrm{ng} / \mathrm{mL})\end{array}$} & \multicolumn{2}{|c|}{ Recovery } & \multicolumn{2}{|c|}{ Matrix Effect } \\
\hline & & Mean \pm SD (\%) & RSD (\%) & Mean \pm SD (\%) & RSD (\%) \\
\hline \multirow{3}{*}{ Curzerene } & 10.20 & $77.08 \pm 0.69$ & 8.75 & $93.35 \pm 0.39$ & 4.64 \\
\hline & 81.30 & $83.46 \pm 4.31$ & 6.35 & $96.86 \pm 4.83$ & 6.90 \\
\hline & 162.00 & $89.60 \pm 6.67$ & 2.29 & $91.40 \pm 7.41$ & 2.33 \\
\hline \multirow{3}{*}{ Methoxyfuranodiene } & 7.90 & $91.11 \pm 0.66$ & 9.14 & $85.71 \pm 0.46$ & 5.45 \\
\hline & 63.00 & $87.57 \pm 3.80$ & 6.89 & $87.06 \pm 4.72$ & 7.45 \\
\hline & 126.00 & $89.76 \pm 7.17$ & 3.17 & $83.10 \pm 6.75$ & 2.48 \\
\hline \multirow{3}{*}{$\beta$-Elemene } & 21.40 & $78.12 \pm 1.10$ & 6.56 & $100.66 \pm 1.40$ & 8.44 \\
\hline & 171.00 & $87.40 \pm 7.93$ & 5.31 & $98.68 \pm 9.76$ & 6.44 \\
\hline & 342.00 & $92.94 \pm 8.48$ & 1.33 & $101.15 \pm 6.52$ & 1.04 \\
\hline \multirow{3}{*}{$\alpha$-Pinene } & 8.00 & $91.25 \pm 0.23$ & 6.35 & $98.69 \pm 0.20$ & 5.52 \\
\hline & 31.80 & $88.27 \pm 1.90$ & 6.76 & $99.47 \pm 1.30$ & 4.60 \\
\hline & 127.00 & $86.98 \pm 3.66$ & 3.32 & $100.50 \pm 7.72$ & 7.02 \\
\hline
\end{tabular}

\subsection{Application to Pharmacokinetic Study in Rats}

The validated assay in this paper was sensitive enough to apply in the pharmacokinetic study of four volatile constituents in rat plasma after oral administration of $C$. myrrh resin extract at a reported therapeutic dose of $500 \mathrm{mg} / \mathrm{kg}$ [30]. The plasma concentration-time curve of the four analytes in rat plasma are shown in Figure 5, and the pharmacokinetic parameters result are summarized in Table 4 . The results showed that curzerene and methoxyfuranodiene were absorbed easily and rapidly after oral administration of $C$. myrrh resin extract, and they achieved maximum plasma concentration $\left(C_{\max }\right)$ after $1 \mathrm{~h}$. However, 
the $T_{\max }$ values were $2 \mathrm{~h}$ for $\beta$-elemene and $\alpha$-pinene, which were absorbed slowly after oral administration. The $C_{\max }$ value of methoxyfuranodiene was achieved to the relatively low level of $95.1 \pm 6.10 \mathrm{ng} / \mathrm{mL}$ after oral administration, these results indicated that the absorbed methoxyfuranodiene might rapidly distribute into the tissues and organs because of its highly lipophilic or as a result of an extensive presystemic metabolism as many drugs may be metabolized before adequate plasma concentrations are reached [31]. On the other hand, the relatively low content of $\alpha$-pinene in C. myrrh resin extract could be contributed to its low plasma concentration. The results also revealed that the elimination processes of the four compounds might be slow, as indicated by the mean residence time (MRT) from the time of dosing to the time of the last measurable concentration $(9.10-34.28 \mathrm{~h})$ moreover the $\mathrm{T}_{1 / 2}$ of the four compounds were more than $7.03 \mathrm{~h}$, the slow elimination could be attributed to the high affinity binding to blood protein or because of the enterohepatic circulation. It is required to be proved by the hepatoenteral pharmacokinetic experiment further.
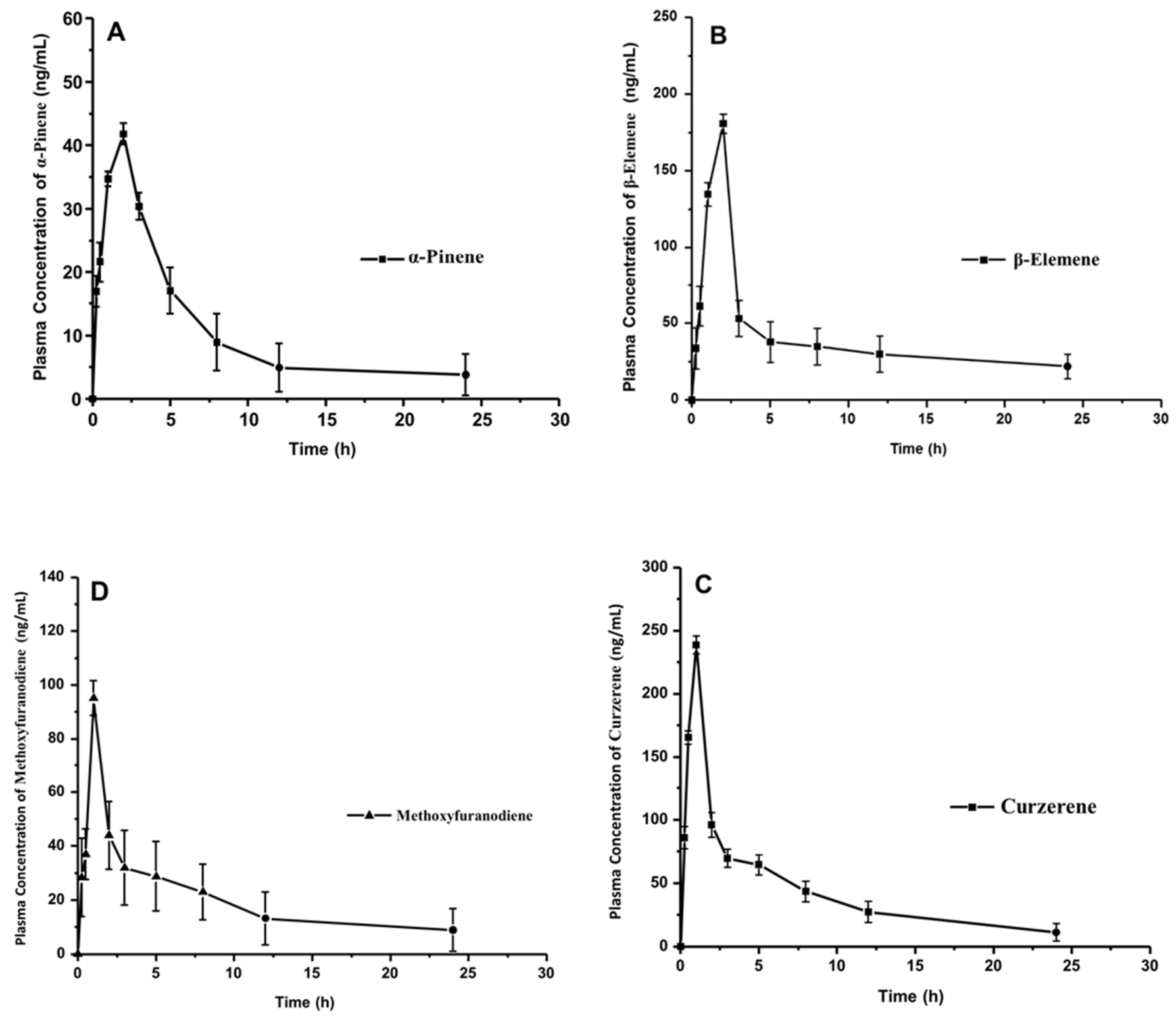

Figure 5. Concentration-time curves of $\alpha$-pinene (A), $\beta$-elemene (B), curzerene (C), and methoxyfuranodiene (D) in rat after oral administration of the C. myrrh resin extract $(n=5)$. 
Table 4. Pharmacokinetic parameters of the four investigated compounds in rats after oral administration of extract of $C$. myrrh resin $(\mathrm{n}=5)$.

\begin{tabular}{|c|c|c|c|c|c|c|c|}
\hline \multirow{2}{*}{ Compound } & $\mathrm{C}_{\max }(\mathrm{ng} / \mathrm{mL})$ & $\mathrm{T}_{\max }(\mathrm{h})$ & $\mathbf{T}_{\frac{1}{2}}(\mathbf{h})$ & $\begin{array}{c}\mathrm{AUC}_{0-24} \\
(\mathrm{ng} \cdot \mathrm{h} / \mathrm{mL})\end{array}$ & $\begin{array}{c}\mathrm{AUC}_{0-\infty} \\
\text { (ng.h/mL) }\end{array}$ & $\operatorname{Kel}\left(h^{-1}\right)$ & MRT (h) \\
\hline & \multicolumn{7}{|c|}{ Values (Mean \pm SD) } \\
\hline Curzerene & $227 \pm 21.98$ & 1 & $7.013 \pm 3.08$ & $1039 \pm 80.32$ & $1147 \pm 117.50$ & $0.148 \pm 0.14$ & $9.10 \pm 2.23$ \\
\hline Methoxyfuranodien & $95.10 \pm 6.10$ & 1 & $11.26 \pm 0.85$ & $495.5 \pm 19.04$ & $640.4 \pm 17.85$ & $0.062 \pm 0.01$ & $15.16 \pm 1.55$ \\
\hline$\beta$-Elemen & $180.90 \pm 11.27$ & 2 & $26.96 \pm 10.40$ & $982.1 \pm 43.59$ & $1845 \pm 332.90$ & $0.028 \pm 0.01$ & $34.28 \pm 13.36$ \\
\hline$\alpha$-Pinene & $43.17 \pm 2.046$ & 2 & $9.379 \pm 5.38$ & $263 \pm 5.51$ & $314.2 \pm 31.54$ & $0.089 \pm 0.03$ & $12.04 \pm 4.75$ \\
\hline
\end{tabular}

W. Li et al. [24] had studied the pharmacokinetics of $\beta$-elemene and $\alpha$-pinene in rat plasma using GC-MS method after administration of oil of Rhizoma curcumae. According to their results, the $C_{\max }$ of $\beta$-elemene and $\alpha$-pinene were $248.98 \mathrm{ng} / \mathrm{mL}$ and $34.72 \mathrm{ng} / \mathrm{mL}$, while the obtained results in this paper are 180.9 and $43.17 \mathrm{ng} / \mathrm{mL}$ for $\beta$-elemene and $\alpha$-pinene, respectively. As far as we know, there is no method for the determination of curzerene and methoxyfuranodiene in plasma in the form of pharmacokinetic studies is available in the literature. The results about the pharmacokinetic profiles of $\beta$-elemen and $\alpha$-pinene in C. myrrh resin in this paper were slightly different from that observed for their pure forms or other herbal prescriptions. These results indicated that the multiple constituents in the C. myrrh resin as well as the interactions among so many compounds in vivo could influence drugs bioavailability, metabolism, and half-life. This is the first report about a pharmacokinetic study of myrrh's bioactive constitute and the results of this work can provide a significant experimental basis for the proper clinical application of C. myrrh resin.

\subsection{Cytotoxicity Activity}

In this study, the antiproliferative activity of these compounds was evaluated against lung carcinoma (A549) and colon (LoVo) cell lines. The results displayed in Figure 6 indicate that each compound caused a variable inhibition on tested cells proliferation and methoxyfuranodiene compound exerted the strong antiproliferative activity against both cell line in terms of $\mathrm{IC}_{50}$ values (Table 5). A similar cytotoxic effect of 2-methoxyfuranodiene was observed in our previous study against breast (MCF-7) and liver (HepG2) cancer cells [18]. In accordance with our results, curzerene from Curcuma longa also exerted antiproliferative effects in human lung cancer cells (SPC-A1) through enhancing apoptosis and cell cycle arrest. However, the reported $\mathrm{IC}_{50}$ in this study is slightly different which could be due to the type of cells and time incubation periods [32]. In addition, the cytotoxic activity of $\alpha$-pinene and $\beta$-elemene is well documented against a variety of cell lines [22,33]. However, this is the first report on the activity of these two compounds isolated from C. myrrh resin against other cell lines indicating that they could be developed as anticancer therapeutics. Further research would be necessary in order to determine the possible mechanism responsible for the observed in vitro studies using detailed molecular mechanisms as well as in vivo anticancer models to give more insight on their biological effects. 
(a)

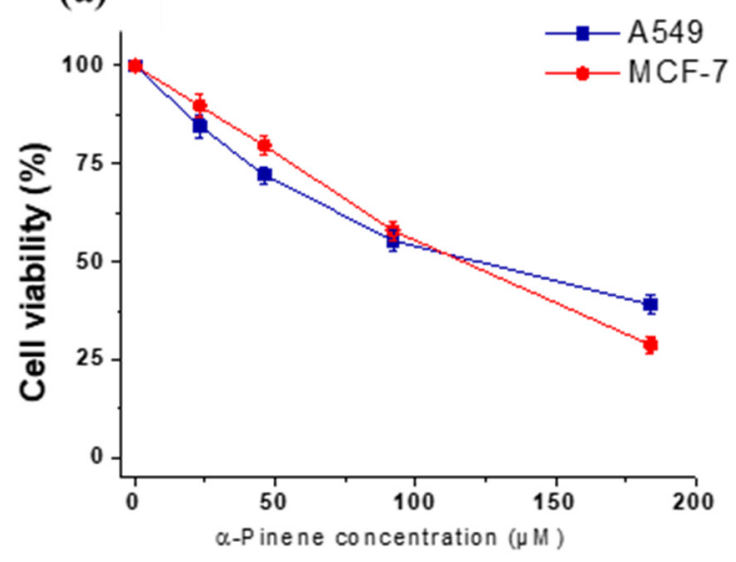

(c)

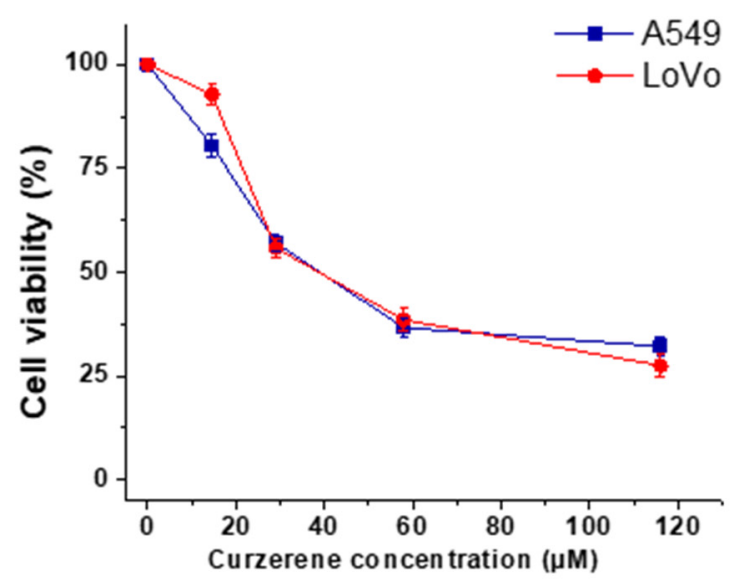

(b)

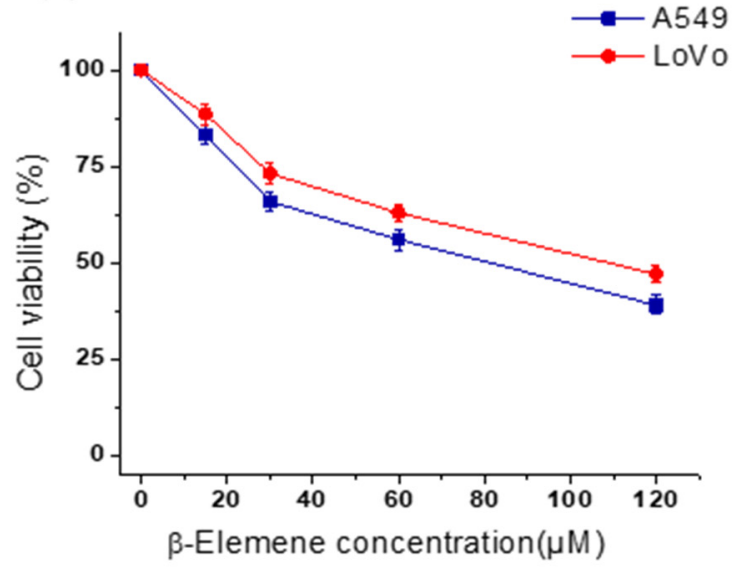

(d)

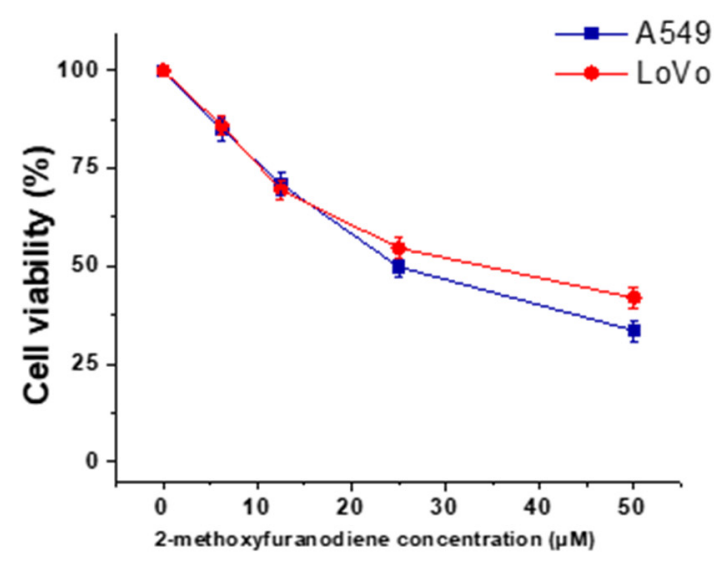

Figure 6. Antiproliferative effect of $\alpha$-pinene (a), $\beta$-elemene (b), curzerene (c), and methoxyfuranodiene (d) on survival of A-549 and LoVo cells. Both Cells were treated with different concentration of each compound $48 \mathrm{~h}$. Cell viability was determined using MTT assay as described in method section. Values are given as average \pm standard error of three experiments.

Table 5. $\mathrm{IC}_{50}$ values of tested compounds against two different cancer cells.

\begin{tabular}{ccc}
\hline \multirow{2}{*}{ Compound } & \multicolumn{2}{c}{ Cell Lines and $\mathrm{IC}_{\mathbf{5 0}}(\boldsymbol{\mu M})$} \\
\cline { 2 - 3 } & $\mathbf{A 5 4 9}$ & LoVo \\
\hline Curzerene & $38.42 \pm 0.18$ & $39.61 \pm 0.41$ \\
\hline Methoxyfuranodiene & $24.81 \pm 0.42$ & $34.74 \pm 0.62$ \\
\hline$\beta$-Elemene & $80.62 \pm 0.36$ & $107.53 \pm 0.51$ \\
\hline$\alpha$-Pinene & $117.51 \pm 0.51$ & $122.33 \pm 0.82$ \\
\hline Doxorubicin & $3.21 \pm 0.16$ & $5.00 \pm 0.34$ \\
\hline
\end{tabular}

\section{Conclusions}

We developed a simple, sensitive, accurate, and selective GC-MS method for the determination of myrrh's bioactive constituents (curzerene, methoxyfuranodiene, $\beta$-elemene, and $\alpha$-pinene) in rat plasma samples. The method was fully validated as per US FDA guidance for bioanalytical method validation, and all the evaluated parameters were within the acceptable limits. The implementation of liquid/liquid extraction techniques and the use of SIM for detection and quantitation resulted in better LOQ, linearity range, and recovery 
for all analyzed compounds. The matrix effect was evaluated and the analytical values confirmed no significant co-eluting endogenous interference existed in the plasma. For the first time, the method was successfully applied in a pharmacokinetic study of Myrrh's bioactive constituents after the oral administration of the extract of C. myrrh resin in rats. The pharmacokinetic parameters of the studied compounds were evaluated including $\mathrm{C}_{\max }, \mathrm{T}_{\max }, \mathrm{AUC}_{0-\mathrm{t}}, \mathrm{AUC}_{0-\infty}, \mathrm{T}_{\frac{1}{2}}, \mathrm{Kel}$, and mean residence time. The cytotoxicity of these volatile compounds was evaluated against different cell lines (colon (LoVo) and lung (A549) cancer cells), were each compound caused variable inhibition on cells proliferation and methoxyfuranodiene exerted the strong activity against both cell lines according to $\mathrm{IC}_{50}$ values. The obtained results can provide valuable experimental information for researchers and technicians for further clinical applications of C. myrrh resin and its prescriptions.

Author Contributions: Conceptualization, A.S.A.; data curation, F.A.; formal analysis, R.N.H., F.A. and S.R.A.; funding acquisition, A.S.A.; methodology, R.N.H., S.R.A. and F.A.N.; resources, A.S.A. and O.M.N.; software, F.A. and S.R.A.; supervision, A.S.A.; validation, R.N.H.; writing-original draft, R.N.H.; writing-review and editing, A.S.A. and R.N.H. All authors have read and agreed to the published version of the manuscript.

Funding: This research was funded by Researchers Supporting Project number (RSP-2021/132), King Saud University, Riyadh, Saudi Arabia.

Institutional Review Board Statement: The Study was conducted after approval of Research Ethics Committee, King Saud University (Reference no. KSU-SE-21-15, dated 3 February 2021).

Informed Consent Statement: Not applicable.

Data Availability Statement: Data is contained within the article.

Acknowledgments: Authors are thankful to the Researchers Supporting Project number (RSP2021/132), King Saud University, Riyadh, Saudi Arabia for funding this research.

Conflicts of Interest: The authors declare no conflict of interest.

\section{References}

1. Başer, K.; Demirci, B.; Dekebo, A.; Dagne, E. Essential oils of some Boswellia spp., myrrh and opopanax. Flavour Fragr. J. 2003, 18, 153-156. [CrossRef]

2. Alqahtani, A.S.; Herqash, R.N.; Noman, O.M.; Tabish Rehman, M.; Shahat, A.A.; Alajmi, M.F.; Nasr, F.A. Impact of Different Extraction Methods on Furanosesquiterpenoids Content and Antibacterial Activity of Commiphora myrrha Resin. J. Anal. Methods Chem. 2021, 2021, 5525173. [CrossRef] [PubMed]

3. Dolara, P.; Luceri, C.; Ghelardini, C.; Monserrat, C.; Aiolli, S.; Luceri, F.; Lodovici, M.; Menichetti, S.; Romanelli, M.N. Analgesic effects of myrrh. Nature 1996, 379, 29. [CrossRef] [PubMed]

4. Alqahtani, A.S.; Noman, O.M.; Rehman, M.T.; Siddiqui, N.A.; Alajmi, M.F.; Nasr, F.A.; Shahat, A.A.; Alam, P. The influence of variations of furanosesquiterpenoids content of commercial samples of myrrh on their biological properties. Saudi Pharm. J. 2019, 27, 981-989. [CrossRef] [PubMed]

5. Su, S.; Wang, T.; Duan, J.A.; Zhou, W.; Hua, Y.Q.; Tang, Y.P.; Yu, L.; Qian, D.W. Anti-inflammatory and analgesic activity of different extracts of Commiphora myrrha. J. Ethnopharmacol. 2011, 134, 251-258. [CrossRef] [PubMed]

6. $\quad$ Lamichhane, R.; Lee, K.H.; Pandeya, P.R.; Sung, K.K.; Lee, S.; Kim, Y.K.; Jung, H.J. Subcutaneous Injection of Myrrh Essential Oil in Mice: Acute and Subacute Toxicity Study. Evid. Based Complement. Alternat. Med. 2019, 2019, 8497980. [CrossRef] [PubMed]

7. Al-Rowais, N.A. Herbal medicine in the treatment of diabetes mellitus. Saudi Med. J. 2002, 23, 1327-1331.

8. El Ashry, E.S.; Rashed, N.; Salama, O.M.; Saleh, A. Components, therapeutic value and uses of myrrh. Pharmazie 2003, 58, 163-168.

9. Zhu, X.F.; Luo, J.; Guan, Y.M.; Yu, Y.T.; Jin, C.; Zhu, W.F.; Liu, H.N. Effects of Frankincense and Myrrh essential oil on transdermal absorption in vitro of Chuanxiong and penetration mechanism of skin blood flow. Zhongguo Zhong Yao Za Zhi 2017, 42, 680-685. [CrossRef]

10. Chevallier, A. The Encyclopedia of Medicinal Plants; Dorling Kindersley limited: London, UK, 1996.

11. Hanus, L.O.; Rezanka, T.; Dembitsky, V.M.; Moussaieff, A. Myrrh-Commiphora chemistry. Biomed. Pap. Med. Fac. Univ. Palacky Olomouc. Czech. Repub. 2005, 149, 3-27. [CrossRef]

12. Chen, Y.; Zhou, C.; Ge, Z.; Liu, Y.; Liu, Y.; Feng, W.; Li, S.; Chen, G.; Wei, T. Composition and potential anticancer activities of essential oils obtained from myrrh and frankincense. Oncol. Lett. 2013, 6, 1140-1146. [CrossRef]

13. Cao, B.; Wei, X.-C.; Xu, X.-R.; Zhang, H.-Z.; Luo, C.-H.; Feng, B.; Xu, R.-C.; Zhao, S.-Y.; Du, X.-J.; Han, L. Seeing the unseen of the combination of two natural resins, frankincense and myrrh: Changes in chemical constituents and pharmacological activities. Molecules 2019, 24, 3076. [CrossRef] 
14. Mahboubi, M.; Mohammad Taghizadeh Kashani, L. The anti-dermatophyte activity of Commiphora molmol. Pharm. Biol. 2016, 54, 720-725. [CrossRef]

15. Hanuš, L.; Rosenthal, D.; Řezanka, T.; Dembitsky, V.; Moussaief, A. Fast and easy GC/MS identification of myrrh resins. Pharm. Chem. J. 2008, 42, 719-720. [CrossRef]

16. Germano, A.; Occhipinti, A.; Barbero, F.; Maffei, M.E. A Pilot Study on Bioactive Constituents and Analgesic Effects of MyrLiq ${ }^{\circledR}$ a Commiphora myrrha Extract with a High Furanodiene Content. Biomed Res. Int. 2017, 2017, 3804356. [CrossRef] [PubMed]

17. Ahamad, S.R.; Al-Ghadeer, A.R.; Ali, R.; Qamar, W.; Aljarboa, S. Analysis of inorganic and organic constituents of myrrh resin by GC-MS and ICP-MS: An emphasis on medicinal assets. Saudi Pharm. J. 2017, 25, 788-794. [CrossRef]

18. Alqahtani, A.S.; Nasr, F.A.; Noman, O.M.; Farooq, M.; Alhawassi, T.; Qamar, W.; El-Gamal, A. Cytotoxic Evaluation and Anti-Angiogenic Effects of Two Furano-Sesquiterpenoids from Commiphora myrrh Resin. Molecules 2020, 25, 1318. [CrossRef] [PubMed]

19. Fang, M.; Mei, X.; Yao, H.; Zhang, T.; Zhang, T.; Lu, N.; Liu, Y.; Xu, W.; Wan, C. $\beta$-elemene enhances anticancer and anti-metastatic effects of osteosarcoma of ligustrazine in vitro and in vivo. Oncol. Lett. 2018, 15, 3957-3964. [CrossRef]

20. Chen, W.; Lu, Y.; Wu, J.; Gao, M.; Wang, A.; Xu, B. Beta-elemene inhibits melanoma growth and metastasis via suppressing vascular endothelial growth factor-mediated angiogenesis. Cancer Chemother. Pharmacol. 2011, 67, 799-808. [CrossRef]

21. Lim, C.B.; Ky, N.; Ng, H.M.; Hamza, M.S.; Zhao, Y. Curcuma wenyujin extract induces apoptosis and inhibits proliferation of human cervical cancer cells in vitro and in vivo. Integr. Cancer Ther. 2010, 9, 36-49. [CrossRef] [PubMed]

22. Salehi, B.; Upadhyay, S.; Orhan, I.E.; Jugran, A.K.; Jayaweera, S.L.; Dias, D.A.; Sharopov, F.; Taheri, Y.; Martins, N.; Baghalpour, N.; et al. Therapeutic Potential of $\alpha$ - and $\beta$-Pinene: A Miracle Gift of Nature. Biomolecules 2019, 9, 738. [CrossRef]

23. Sun, S.; Wang, Y.; Wu, A.; Ding, Z.; Liu, X. Influence Factors of the Pharmacokinetics of Herbal Resourced Compounds in Clinical Practice. Evid. Based Complement. Alternat. Med. 2019, 2019, 1983780. [CrossRef]

24. Li, W.; Hong, B.; Li, Z.; Li, Q.; Bi, K. GC-MS method for determination and pharmacokinetic study of seven volatile constituents in rat plasma after oral administration of the essential oil of Rhizoma curcumae. J. Pharm. Biomed. Anal. 2018, 149, 577-585. [CrossRef] [PubMed]

25. Papada, E.; Gioxari, A.; Amerikanou, C.; Galanis, N.; Kaliora, A.C. An Absorption and Plasma Kinetics Study of Monoterpenes Present in Mastiha Oil in Humans. Foods 2020, 9, 1019. [CrossRef]

26. Chen, Z.; Song, Y.; Che, J.; Liu, X.; Ning, Y.; Shan, C.; Hou, Y.; Liu, Y.; Miao, X.; Cheng, Y. Validation of a sensitive gas chromatographic-mass spectrometric method for the simultaneous determination of beta-elemene and beta-elemenal in human plasma. J. Chromatogr. B Analyt. Technol. Biomed. Life Sci. 2009, 877, 408-414. [CrossRef] [PubMed]

27. Bhattaram, V.A.; Graefe, U.; Kohlert, C.; Veit, M.; Derendorf, H. Pharmacokinetics and bioavailability of herbal medicinal products. Phytomedicine 2002, 9 (Suppl. 3), 1-33. [CrossRef] [PubMed]

28. Zhang, X.; Zheng, W.; Xu, H.; Huang, X.; Ren, P.; Zou, H.; Liu, G.; Wang, J.; Ma, X. Pharmacokinetic study of representative anti-oxidative compounds from Denshen-Chuanxiong-Honghua following oral administration in rats. J. Chromatogr. B Analyt. Technol. Biomed. Life Sci. 2017, 1052, 82-90. [CrossRef] [PubMed]

29. Nasr, F.A.; Shahat, A.A.; Alqahtani, A.S.; Ahmed, M.Z.; Qamar, W.; Al-Mishari, A.A.; Almoqbil, A.N. Centaurea bruguierana inhibits cell proliferation, causes cell cycle arrest, and induces apoptosis in human MCF-7 breast carcinoma cells. Mol. Biol. Rep. 2020, 47, 6043-6051. [CrossRef]

30. Ahmad, A.; Raish, M.; Ganaie, M.A.; Ahmad, S.R.; Mohsin, K.; Al-Jenoobi, F.I.; Al-Mohizea, A.M.; Alkharfy, K.M. Hepatoprotective effect of Commiphora myrrha against d-GalN/LPS-induced hepatic injury in a rat model through attenuation of pro inflammatory cytokines and related genes. Pharm. Biol. 2015, 53, 1759-1767. [CrossRef]

31. Version, M.M.P. Clinical Pharmacology (Pharmacokinetics): Drug Bioavailability. Available online: https://www.msdmanuals $\mathrm{com} /$ professional/clinical-pharmacology/pharmacokinetics/drug-bioavailability (accessed on 27 October 2021).

32. Wang, Y.; Li, J.; Guo, J.; Wang, Q.; Zhu, S.; Gao, S.; Yang, C.; Wei, M.; Pan, X.; Zhu, W.; et al. Cytotoxic and Antitumor Effects of Curzerene from Curcuma longa. Planta Med. 2017, 83, 23-29. [CrossRef]

33. Jiang, Z.; Jacob, J.A.; Loganathachetti, D.S.; Nainangu, P.; Chen, B. $\beta$-Elemene: Mechanistic Studies on Cancer Cell Interaction and Its Chemosensitization Effect. Front. Pharmacol. 2017, 8, 105. [CrossRef] [PubMed] 